\title{
Influencing Factors of Success and Failure in MOOC and General Analysis of Learner Behavior
}

\author{
Laxmisha Rai and Deng Chunrao
}

\begin{abstract}
In this paper, we argue that, success and failures in online learning is mostly depending on personal factors rather than factors influenced by the surroundings or the external environment. Students' individual behavior plays an important role in learning. However, this may not be the case in classroom-based learning or time-tested traditional practices of learning, where multiple students learn together, as well as teachers influence the underperforming students to perform better. In this paper, we explore comparisons between learner behavior in hierarchical individual mode or traditional classroom learning and in online courses such as Massive Open Online Courses (MOOC). MOOC learning belongs to the distributed individual mode of learning. The study is based on analyzing the learner's interests and understanding within such modes. The information is gathered based on results available since the introduction of MOOC from the reputed universities in the world and on the general opinions derived from perspectives of MOOC learners.
\end{abstract}

Index Terms-MOOC, online, behavior, learning.

\section{INTRODUCTION}

Information technology has been playing a major role in modern teaching and learning. Before the wide spread use of information technology, the traditional chalk-and-talk method was used as a primary way of teaching, where teachers used a chalk to write on a blackboard and then deliver a lecture [1]. In many universities these methods are now replaced by Power-Point (PPT) presentation. It is easy for learners to absorb ideas in a PPT presentation, and teacher can show a number of audio or video information by embedding them within a slide. So, what methods need to be retained or discarded is a big question mark among teachers. Besides the use of Power-Point presentations, online materials seem to be very easy to gather right information. Moreover, it is easy to produce multiple copies for distribution. However, having overloaded and high-quality information does not necessarily prove the abilities of a learner or teacher. A teacher must know what information is right and best for students. At the same time, students must know how to learn or catch up with lessons more efficiently. Unfortunately, providing best ideas to learn does not really help students because they fail to provide best process of learning, and students fail to practice real-life situations during learning. For example, in the traditional classrooms, students need to be aware of classroom conditions strictly and need to take notes actively

Manuscript received August 30, 2014; revised November 9, 2014.

Laxmisha Rai is with the Shandong University of Science and Technology, Qingdao, 266590, P.R. China (e-mail: laxmisha@ieee.org).

Deng Chunrao is with the Hong Kong Polytechnic University, Hong Kong (e-mail: ccjdeng@hkcc-polyu.edu.hk). while listening to their teachers. They also learn how to live with fellow classmates, how to talk to teachers in person, and how to participate in different academic competitions. This not only improves them psychologically but also physically.

In this century, technological innovations have been influenced heavily on educational practices. Learners and teachers both practice novel and innovative ideas for improving the quality of teaching, learning, disseminating ideas, and knowledge sharing. However, in the age of technological innovation, it is challenging for them to retain some of the time-tested and reliable practices which had been followed for thousands of years. Innovation is the key to the success of any educational organization. In the past few years, many scholars wrote extensive articles and books regarding online teaching and learning. For example, Lee Chao wrote about open source tools for online teaching and learning [2]. Ormond Simpson wrote about student retention in online, open, and distance learning [3]. Judith V. Boettcher and Rita-Marie Conrad wrote a guide of how to survive in online teaching, along with simple and practical pedagogical tips [4]. Karen Swan explored learner interactions with course content, student interactions with instructors, and interactions among classmates in online course environments [5].

A few decades back, both teachers and students suffered from the availability of course and learning materials, especially in developing and under-developed countries. Today the trend is changing. One of the factors responsible for this change is the development of IT tools, which change the methods of teaching and learning. The IT developments make us easy to obtain great amount of materials through various media such as Internet, TV, and smart phone, etc. However, students seem to be in the losing side irrespective of these developments.

In this paper, we would like to explore the general behavior of online learners and the influencing factors of success and failures of MOOC platform. In recent years, Massive Open Online Courses (MOOCs) has been attracted millions of learners around the world, through various MOOC providers such as edX, Coursera, and Udacity. MOOC facilitates millions of learners to enroll courses form reputed universities around the world such as Harvard University, Stanford University, Massachusetts Institute of Technology (MIT), University California at Berkeley (UCB) etc. Some of courses provided by these universities include Introduction to Computer Science, Software as a Service, Principles of Written English, Cyber-Physical Systems, and Circuits and Electronics etc. However, based on the existing reports available, success rate in these kinds of MOOC courses is less than $7 \%$ on an average. In this paper, we would like to analyze reasons for such a low percentage of success rate, and also list 
the contributing factors for success and failure in a MOOC.

\section{MOOC AND ONLINE LEARNING}

In 2012, both MIT and Harvard University decided to offer wide-range of university-level courses. Students can get a certificate once they finish a course successfully through edX. MOOC platforms such as edX, Coursera, and Udacity derive a number of interesting facts about the future of education. As per New York Times, "The shimmery hope is that free courses can bring the best education in the world to the most remote corners of the planet, help people in their careers, and expand intellectual and personal networks." [6]. As edX, Coursera, and Udacity continue to build and launch MOOCs, other would-be contenders also approach the field. Evidence and opinions are accumulating about how to use such courses, the experience of learning this way, and possible applications of the evolving technology [7].

TABLE I: MOOC PROVIDERS AVAILABLE FOR FREE EDUCATION

\begin{tabular}{|l|l|}
\hline \multicolumn{1}{|c|}{ Organization } & \multicolumn{1}{c|}{ Description } \\
\hline (wwlor & $\begin{array}{l}\text { Free education initiative with 294 courses } \\
\text { representing 10 of the highest enrollment } \\
\text { majors in the US. }\end{array}$ \\
\hline $\begin{array}{l}\text { Coursera } \\
\text { (www.coursera.org) }\end{array}$ & $\begin{array}{l}\text { An educational technology company } \\
\text { offering free online courses founded by } \\
\text { computer science professors Andrew Ng and } \\
\text { Daphne Koller from Stanford University. } \\
\text { Currently, Coursera has 7.1 million users in } \\
\text { 641 courses from 108 institutions. }\end{array}$ \\
\hline $\begin{array}{l}\text { Udacity } \\
\text { (www.udacity.com) }\end{array}$ & $\begin{array}{l}\text { A private educational organization founded } \\
\text { by Sebastian Thrun, David Stavens, and } \\
\text { Mike Sokolsky offering massive open online } \\
\text { courses(MOOC). Currently, Udacity has 1.6 } \\
\text { million users in 12 full courses and 26 free } \\
\text { courseware. }\end{array}$ \\
\hline $\begin{array}{l}\text { edX } \\
\text { (www.edx.org) }\end{array}$ & $\begin{array}{l}\text { edX is a MOOC platform founded by MIT } \\
\text { and Harvard University to offer online } \\
\text { university-level courses in a wide range of } \\
\text { disciplines to a worldwide audience at no } \\
\text { charge. Currently, edX has more than 2.5 } \\
\text { million users taking over 240 courses online. }\end{array}$ \\
\hline $\begin{array}{l}\text { Iversity } \\
\text { (https://iversity.org) }\end{array}$ & $\begin{array}{l}\text { iversity.org is a MOOC provider, } \\
\text { established in October 2013, based in } \\
\text { Bernau bei Berlin, Germany, currently with } \\
\text { with 24 MOOCs and over 100,000 users }\end{array}$ \\
\hline $\begin{array}{l}\text { Futurelearn } \\
\text { (www.futurelearn.com) }\end{array}$ & $\begin{array}{l}\text { FutureLearn is UK-based massive open } \\
\text { online course (MOOC) learning platforms } \\
\text { founded in December 2012 include courses } \\
\text { from 20 of the best UK and international } \\
\text { universities. }\end{array}$ \\
\hline
\end{tabular}

Some of the widely used MOOC providers are listed in Table I. Most of the courses are absolutely free of cost, and taught by professors from leading universities in the world such as Harvard University, MIT, Stanford University, etc. There are also options to get verified certificates after paying a minimum fee. With this, it is evident that there is no problem in obtaining most of the course materials for free of charge. Moreover, all kinds of materials are available today, for example, materials in the form as text files (mostly PDF, Word and PowerPoint), audio, and video lectures, either through MOOC platforms or university websites. One could obtain any level of course materials, in any formats, and also in multiple language subtitles. Students' learning behaviors could be different from those in the traditional classrooms, where students have face-to-face contact with teachers, they need to follow classroom disciplines and have less flexibility in terms of timings for attending classes. As the MOOCs are getting wide attention in these days, we would like to analyze the common behaviors of learners which contribute to the success and failure in MOOC.

\section{LOW SUCCESS RATE IN MOOC}

The success rate of most popular MOOC courses in the recent years show that many online learners lose interest only after a few weeks of course progress. According to the UK's government report on MOOC, "The MOOC format itself suffers from weaknesses around access, content, quality of learning, accreditation, pedagogy, poor engagement of weaker learners, exclusion of learners without specific networking skills"[8]. According to 2013 data compiled by an Open University doctoral student, Katy Jordan, as part of her own MOOC studies, the average completion rate for massive open online courses is less than 7\%. According to her findings, which are based on local news articles, university documents, presentations and other information sources (including Times Higher Education), the average MOOC completion rate across the 29 courses was just 6.8 per cent [9]. In another example, of the 841,687 students enrolled at Harvard and the Massachusetts Institute of Technology, 5\% earned such a certificate [10]. However, it is worth noting that, mere completion doesn't mean that MOOCs are ineffective. There are many cases where students joined MOOC only to audit the courses or to have some exposure from the best universities in the world. So, benefits of MOOC courses are still many. The main reason for this kind of low completion rate, (here completion rate actually means, the students who obtained the certificates) is: different universities set different criteria for completion rate, and many students feel that online courses are just for the sake of providing knowledge, and completing the course is not necessary at all. So, failure to finish a MOOC course is not complete failure at all. This may apply to success in MOOC as well. For example, some courses in MOOC are totally auto-graded, or graded by the computer, so if one is lucky, he/she may simply get a certificate without even listening to lectures or understanding the problems. In other words, students might not take online courses seriously as they do in the traditional classroom settings.

\section{REASONS FOR FAILURES IN MOOC}

In this section, we would like to list the reasons of failures in a MOOC from the learner's perspective. We have listed a couple of reasons for this trend as compared to traditional time-tested practices.

\section{A. Learners as Information Viewers, or Collectors Rather than Active Users}

In [11], researchers identified five styles of engagement in MOOC: Viewers, Solvers, All-rounders, Collectors, and Bystanders. Irrespective of all these high-quality course materials available freely to students through MOOC, a number of negative trends are growing among learners.

1) Learners are increasingly focusing on collecting and storing materials as much they can without using it. 
2) Learners are not guided properly to identify how many materials are needed, useful, and required at their level to complete the course successfully.

3) Learners are increasingly interested in audio, video, and Power-Point (PPT) materials than simply textbook (or text) materials.

4) The face-to-face meeting with fellow-learners and problem solving chances along other peers are diminishing, as most of them depend on discussion forums for asking and answering questions.

The above reasons make the online learners passive. According to Terry Anderson [12], "Just as there are many kinds and subject focus of MOOCs, there are many different types of students attracted and they have wide variety of expectations and commitments. Early research is showing that many students enroll in MOOCs as auditors with no intention of completing assignments or quizzes. They may just be curious, be testing the waters, experiencing how other teachers handle the teaching or just curious about MOOCs. These students are usually passive participants, or lurkers, who may drop out (or even drop in to active participation) later in the course."

\section{B. Minimum Learning by Doing}

In essence, modern innovative education tools help to students to understand what to learn, but fail to produce enough interest on how to learn, and also fail to produce critical thinking among students. Education itself is suffering from overburdened information in the web (such as Google, Wikipedia). Today every course material and homework is on the Internet; anything can be copied at any time. Students almost forget how to write with pens and pencils. In other words, the traditional values of education are diminishing. The ability to learn by doing is decreasing. For example, it is argued that online lessons, e-Education and MOOCs are effective. But they are only fit to provide theoretical education Change will happen, but definitely time-tested practices never remain obsolete in the teaching practices. For example, there are dual opinions about success and failure of E-learning mechanism. Some experts view that failure in E-learning can occur at three interlocking levels: the product level (poor course design; inadequate technology infrastructure); the learner level (poorly prepared learners, lack of motivation, no time); or the organizational level (low managerial support, lack of reward structure) [13], [14]. Also, there are cases where E-learning mechanisms may fail because of other factors, such as availability of overloaded information and difficulty in identifying right information. Moreover, there is little scope for switching back to traditional models of learning. In this situation, there should be balance between them.

Most of the learning models available today are based upon developed countries' educational traditions. Therefore, it is necessary to analyze some differences in educational traditions that affect the ways in which teaching and learning are viewed. Learning by "doing" is a theme that many educators have stressed since John Dewey's convincing argument that children must be engaged in an active quest for learning new ideas. Students should be presented with real-life problems and then helped to discover information required to solve them [15]. Learner-centered learning changes the focus from teaching to learning, and support learners to develop self-directed learning. Learning by doing takes a deep role, especially in most of the courses related to science and technology. Today, most of the courses in edX are related to computer programming, science and technology. However, hands-on-experience is needed to master skills in these courses, as per famous MIT professor Seymour Papert, "Knowledge is only part of understanding. Genuine understanding comes from hands-on experience" [16], so it is not enough to simply provide knowledge without practical, and method-supporting hands-on experience tools.

\section{Lack of Personal Support and Human Intervention}

In this section, we would like to stress the importance of human intervention in general kinds of learning rather than complete machine-supported or auto-graded system of learning. Students are motivated to learn when the teacher or facilitator is present within their proximity of reach with a closed and systematic support system. Considering the first MOOC form Harvard University, and MIT, the following statistics are available from [17].

- Harvard Computer science lecturer David J. Malan tracked the number of students who were engaged with his virtual course (offered through edX), CS50x: Introduction to Computer Science I, from start to finish. Out of the 150,349 students who registered for CS50x, 10,905 submitted the first problem set. Of that group, 3381 individuals said they hoped to get a certificate out of the course, and only 1388 actually received one.

- According to data collected by MITx with funds from the National Science Foundation, that same trajectory occurred in Anath Agarwal's course 6.002x: Circuits and Electronics, for which 154,763 people registered, 26,349 turned in the first problem set, 9,318 students passed the midterm, and 7,157 ended up certified.

In the case of Harvard University comparing the number of students registered for the course, the completion rate is just below 1\%. However, by contrast, 703 out of 706 students (99.6\%) "Completed" CS50 on campus, which is the same course offered by the same lecturer. This simply shows the difference of results with and without human intervention. However, there may be other factors for the success in campus learning as well as failures in MOOC learning, but the difference level of success rate in both cases is incomparable.

What is the situation, if the MOOC is offered by the one campus and also students are from the same campus? In this scenario, the success rate is a bit higher, but not impressive. For example, the sample size at Wake Technical Community College was much smaller and the completion rate was only marginally better. But of the 14,067 students who signed up for the Introductory Algebra MOOC offered by Wake Tech, 6.2 percent earned a certificate of completion. For comparison, of the 841,687 students enrolled at Harvard and the Massachusetts Institute of Technology, 5 percent earned such a certificate [10].

\section{High Difficulty Level and Lack of Self-Motivation}

Currently, the courses offered by the MOOC platform are mostly from reputed universities in the world such as Harvard, 
MIT, and UCB etc. Most of the courses are taught in the respective university campuses as well. As most online learners enthusiastically join these courses to obtain certifications form these universities, they fail to analyze the level of difficulty of these courses. For example, it is easy to design too many homework, puzzles, assignments, and twisted questions in online platform. Fig. 1 shows one such example, where the course include 6 lab exercises, 26 problem sets, a final project and a final exam, which normally overburden a MOOC learner.

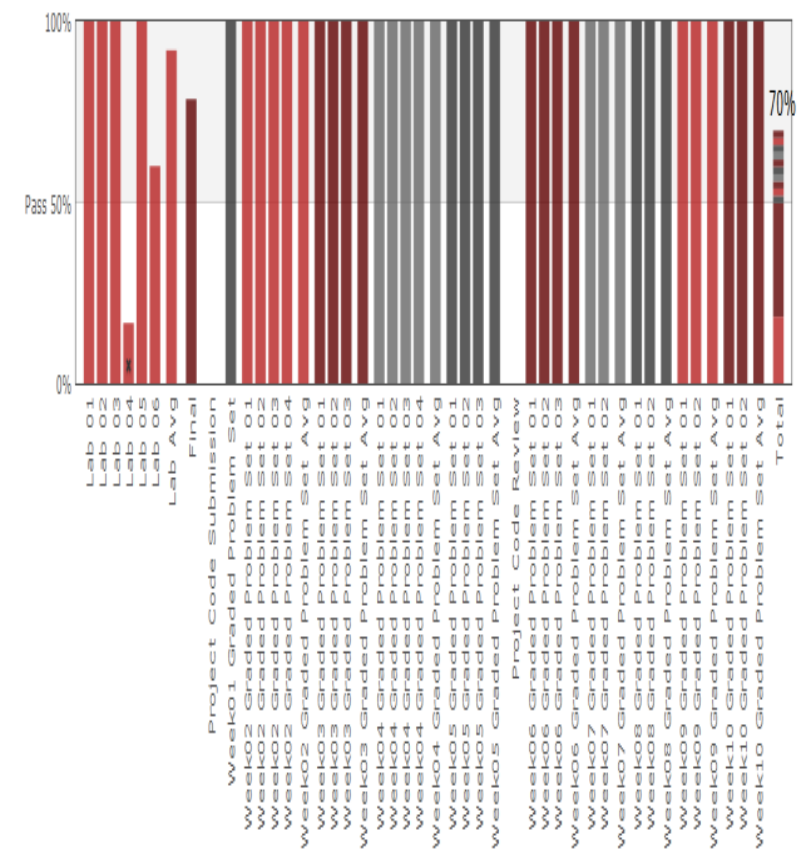

Fig. 1. Progress chart (of first author) showing multiple-lab exercises, problem sets in Introduction to Computing with Java course offered (through edX) by Hong Kong University of Science and Technology.

Moreover, it also easy for the course provider to add many online websites for further reading. So, for an average learner in the remote part corner of this world, too much time and effort is needed to master such course materials. In the case of Harvard University, CS50x: Introduction to Computer Science I, each lecture of a week needs minimum 10 hours of full-time effort, rather than simply 3-4 hours as expected from the course staff. Moreover, the difficulty level increases from the beginning to end. Fig. 2 from the website of this course lecturer shows diminishing trend of submission of problem sets [18]. For example, the number of students completed the first homework is 10,905 , as compared to 1,482 , the number of students finished the final project assignment.

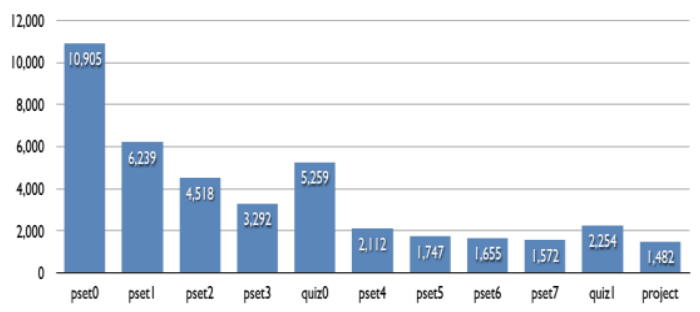

Fig. 2. Submissions of problem sets and quizzes trend in a Harvard MOOC.

Most online learner also faces the problem of complete localization of the materials presented. For example, most of the instructors set their courses to meet the demands of the students in their campuses rather than geographically spread online learners. This forces the online learners to master working or study culture of the offering University. For example, problems set by the teacher from US university fits to the audience of American students, rather than students from either India or China. The similar situation could be observed, if the course is offered from India or China.

It is observed that learners lack self-motivation to complete the course, or to finish homework. As the level of difficulty gets higher, there is huge possibility of students leaving the course abruptly as shown in the Fig. 2. In the campus learning, students are self-motivated by observing others work or motivated to learn together in a face-face environment. Moreover, the purpose of their learning is clearly defined within the context, and students put high priority on on-campus courses. Teachers and their teaching assistants also can motivate students to finish their homework within a campus, which is totally missing in online environment. In traditional university environments, grades provide learners with a huge incentive to attend class and engage with the material. Such an incentive does not exist in MOOCs, completion commonly results in a digital badge or a certificate that often contains little value [19]. In the real classroom settings, some students are motivated to learn their best, as they have chances to win prizes, medals, or gifts for scoring the top in a particular subject from their respective teacher or university, which is hard to implement in a free online learning environment.

\section{E. Uncontrolled and Undisciplined Environment}

In a physical classroom, students are expected to attend the class regularly, and teachers also expected to increase their quality of teaching, and bring innovation into their teaching styles. Moreover, in many countries, minimum student attendance is a basic criterial to decide the level of student participation in a course, and serves as basic criterial to analyses the students' academic progress. For example, India's reputed Manipal Institute of Technology makes it mandatory for a student to have a minimum of $75 \%$ attendance in individual subjects to be eligible to write the end-semester examination, in compliance with the University norms [20]. However such kinds of evaluating students based on student participation is not done systematically in MOOC. In the context of MOOCs, students have substantially more freedom to determine what, when, where, and how they will learn. The barrier to entry is low, and there is no penalty for dropout [21]. Even though it is easy to find such participation results based on the number of times student logged-in the course website, or based on the hours spend watching a particular lecture video, there is no guarantee that this kind of online actions are really done by the exact learner. There is high possibility that, candidate A may help candidate $\mathrm{B}$, using candidate B's login name and password. Moreover, while browsing online course, students are easy to get distracted, for example, watching too many YouTube videos, or playing computer games, which contribute to the uncontrolled and undisciplined environment. From the experience of Udacity, if students don't put in the right kind of work, with the right guidance and expend sufficient cognitive effort, they will not see results. The fundamental understanding of quality online 
learning in higher education was mostly lost or ignored in the MOOC hype. Watching videos of lectures and answering multiple-choice questions is hardly cutting edge pedagogy [22].

\section{REASONS FOR SUCCESS IN MOOC}

\section{A. Enthusiastic and Self-Motivated Learners}

Considering the educational qualifications of edX MOOC learners, most of them are in their high-school level or obtained minimum high-school qualification, or with above bachelor degree qualification. In the case of first MOOC course offered by MIT, 6.002x: Circuits and Electronics, the highest percentage of participants $(36.63 \%)$ were reported having a bachelor's degree [22]. This shows that it is hard to define common educational background for MOOC learners. However, the main motivating factor among all learners is enthusiasm and self-motivation. From the most existing surveys, there are some students in the world, who have completed more than 40 MOOC courses successfully and obtained the certificates. For example, Wang Zhen, computational modeling employee from China earned over 40 certificates and over 30 of them from Coursera [23]. As teachers working in university level, the first and second authors of this paper completed 20 and four MOOC courses respectively. Some learners are motivated to show their talent in self-directed learning, and others genuinely interested in acquiring more knowledge. Similar results were found in the first MOOC course offered by MIT, where the primary motivation of most learners was driven by a desire to gain knowledge and skills, followed by a desire for personal challenge [22]. The survival analysis results conducted by Wen et al. [24] validate that the more motivation the learner expresses, the lower the risk of dropout. Similarly, the more personal interpretation a participant shows in posts, the lower the rate of student dropout from the course forums.

\section{B. Job and Career Requirements}

The second motivating factor for learning in a MOOC environment is regarding job and career requirements. This can be derived from the age range and educational qualification of MOOC learners. In some courses, candidates with Ph.D. also joined MOOC courses. Comparing the results from Udacity, the retention rates in Udacity courses have been abysmal and those that did make it through were those who have already obtained bachelor degrees [25]. There are also cases, where some high school students who took edX courses from MIT were later admitted to MIT [26]. From the discussion forums from edX courses, some MOOC learners joined this course either for improving their prospects in their workplace or to enhance skills, which may boost their career choices. For example, some of the working teachers are acquiring courses such as: ECFS312x Positive Behavior Support in Early Childhood Education, or ECFS311x Becoming a Resilient Person: The Science of Stress Management and Promoting Wellbeing, offered from University of Washington, simply because that provides better skills in managing their students at the early stage of their development.

\section{Authenticated Certificates}

Another motivation to participation in MOOC is their authenticated certifications. This is especially true in case of edX. edX provides certificates, which are issued online, and also can be authenticated by the link provided within certificate. So, there is zero possibility for faking the certificates. Some universities award credits for MOOC courses after finding the rigor of edX courses. For instance, American Council on Education has approved some of the MOOC courses [27]. Moreover, San Jose State University is partnering with Udacity to offer a course for credit [28]. Some company recruiters are hopeful of the value of certificates. For example, a Dell recruiter reported: "A certificate could sweeten an applicant's résumé, but only for those who already hold a four-year degree", says Lisa Soto Hegner, a recruiter for Dell. "It definitely holds some weight... How much I couldn't say, but it would give them some competitive advantage." [29]

\section{University and Teacher Reputations}

Compared to many MOOC providers, in the recent years, edX platform is getting high -attention. For example, in China edX platform is used as an international MOOC provider for Chinese students. Most of the information is provided in Chinese, and many English courses are offered with Chinese subtitles in a separate provider named XuetangX [30]. Currently, edX has partnered with over 40 top universities in the world. Most students joined these MOOC courses because of the reputation of these universities in their respective countries as it is prestige for a learner to get certifications from such universities. In addition, teacher reputation also matters. In [31], the author listed top five MOOC brilliant professors extremely good at teaching and attracting several thousands to over 100,000 students to their virtual classrooms.

\section{E. Flexibility to Make Mistakes, and Instant Feedback}

In MOOC, there is flexibility to make mistakes, and learn by making mistakes. For example, in some courses, a learner can attempt as many answers as possible. As per founder president of edX, Ananth Agarwal, there are six advantages of MOOC learning [32]. Firstly, a learner doesn't have to sit all the time to listen to lecture a in a classroom. He believes that, learning from video with short duration is contributed to active learning. Secondly, there is instant feedback about the assignments and answers submitted by the learners. This is proved in computer literatures as best way to learn and make progress. Thirdly, students are allowed to make many mistakes and this contributes to infinite learning or mastery-based learning. Fourthly, the students are allowed to pause, rewind, speed up/down the video, so that they can listen more and more, which is totally impossible in real-classrooms. Fifth, there is more engagement from learners or gamification. Finally, students learn from their peers, and with thousands of discussions and online forums.

Learners are also able to check their progress of their course towards obtaining a certificate or completing a course successfully, as they make progress. This also provides a flexibility to complete a course within a short time, provides inspiration to move forward in case of courses with fixed 
deadlines. For example, Fig. 3 shows how the progress chart helps the candidate to check the progress instantly, without delay.

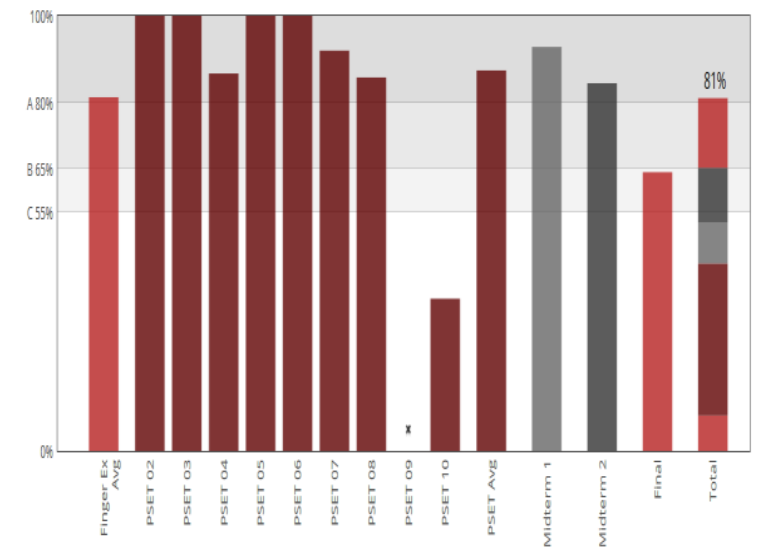

Fig. 3. Progress chart of (of first author) for the course Introduction to Computer Science and Programming offered by MIT through edX.

\section{CONCLUSION}

Technological innovation will transform not only how we teach (or learn) but also what we teach (or learn). The rapid advancing scientific areas such as the brain sciences, artificial intelligence and the psychology of learning will influence conceptual basis of teaching and learning. The challenge for educational organizations such as universities and colleges is to learn from these innovations and to incorporate what is new and helpful. Therefore, teachers need to adopt a rational integration which integrates modern teaching techniques and traditional pedagogical model for higher achievement.

Massive Open Online Courses is a recent trend in education, and there are numerous studies and research. Although MOOC is a very positive trend in education, the attractiveness of its role in student leaning is decreasing. Success is not as expected. This paper reviews some of the reasons for success as well as failures of learners in MOOC. Most of the factors of success or failure are purely individual as most of learners are genuinely interested in finishing course, and most of such learners are fascinated by the reputation of universities, quality of courses, and deriving fun in solving challenging assignments. Other related problems such as poor Internet connectivity, lack of knowledge about MOOC, language barrier and level of learning potential is not considered in this paper.

The role of MOOC cannot be neglected in the future, especially their potential to reach millions of learners around the world. However, as most of the universities are still prototyping and analyzing the loopholes exists in MOOC-based education, it is important to analyze the effectiveness from learners' than providers' perspective. MOOC must focus on attracting more students by providing better tools for learning rather than simply as repositories of high-quality multimedia materials online, then only the effort of MOOC providers will be fruitful.

\section{REFERENCES}

[1] D. E. Shallcross and T. G. Harrison, "Lectures: Electronic presentations versus chalk and talk - A chemist's view," Chemistry Education Research and Practice, 2007, vol. 8, no. 1, pp. 73-79.
[2] L. Chao, "Utilizing open source tools for online teaching and learning Applying linux technologies," Information Science Reference, IGI Global, 2009.

[3] O. Simpson, Student retention in Online, Open and Distance Learning, Kogan Page Limited, 2005.

[4] J. V. Boettcher and R.-M. Conrad, "The online teaching survival guide," Simple and Practical Pedagogical Tips, Jossey-Bass, 2010.

[5] K. Swan, "Learning effectiveness online: What the research tells us," in J. Bourne and J. C. Moore, Eds., Elements of Quality Online Education, Practice and Direction, Needham, MA: Sloan Center for Online Education, pp. 13-45, 2003.

[6] L. Pappano. (2012). The Year of the MOOC. [Online]. Available http://www.nytimes.com/2012/11/04/education/edlife/massive-openonline-courses-are-multiplying-at-a-rapid-pace.html?pagewanted=all \&_ $\mathrm{r}=0$

[7] Differences of Opinion on Online Courses. (June 2013). Harvard Magazine. [Online]. Available: http://harvardmagazine.com/2013/05/harvardx-and-edx-online-learni ng-update

[8] The Maturing of the MOOC: Literature Review of Massive Open Online Courses and other Forms of Online and Distance Learning. (September 2013). [Online]. Available: https://www.gov.uk/government/uploads/system/uploads/attachment_ data/file/240193/13-1173-maturing-of-the-mooc.pdf

[9] C. Parr. (May 2013). MOOC Completion Rates 'below 7\%', Times Higher Education. [Online]. Available: http://www.timeshighereducation.co.uk/news/mooc-completion-ratesbelow-7/2003710.article

[10] J. de Bruyn. (August 2014). Wake Tech Beats Harvard/MIT in MOOC Completion Percentage. [Online]. Available: http://www.bizjournals.com/triangle/news/2014/08/05/wake-tech-bea ts-harvard-mit-mooc-completion.html

[11] A. Anderson, D. Huttenlocher, J. Kleinberg, and J. Leskovec, "Engaging with massive online courses," presented at International World Wide Web Conference Committee (IW3C2), 2014.

[12] T. Anderson. (March 2013). Promise and/or Peril: MOOCs and Open and Distance Education. [Online]. Available: http://www.col.org/SiteCollectionDocuments/MOOCsPromisePeril_ Anderson.pdf

[13] A. Romiszowski. (July 2010). The Future of e-Learning as an Educational Innovation: Factors Influencing Project Success and Failure. [Online]. Available: http://www.abed.org.br

[14] V. Phillips. (June 2002). Why does Corporate e-Learning Fail? Virtual University Gazette. [Online]. Available: http://www.geteducated.com/vug/june02/vug0602.htm

[15] Active Learning. (2014). ERIC Digest No. 17. [Online]. Available: http://ericae.net/edo/ed253468.htm

[16] S. Papert. Constructivism. [Online]. Available: http://gradcourses.rio.edu/themes/constructivism.htm

[17] The edX Student. (2014). [Online]. Available http://www.thecrimson.com/article/2013/5/30/the-edX-student-intern ational/?page $=1$

[18] D. J. Malan. (April 2013). This was CS50X. [Online]. Available: https://blog.cs50.net

[19] S. Jiang, A. Williams, K. Schenke, M. Warschauer, amd D. O’Dowd, "Predicting MOOC performance with week 1 behavior," in Proc. the 7 th International Conference Educational Data Mining, London, pp. 273-275, July 2014

[20] Engineering. (2014). MIT Manipal-Attendance Rules and Regulations. [Online]. Available: http://www.manipal.edu/institutions/engineeringandit/mit/student $\% 2$ 7 scorner/rulesandregulations/pages/studentattendanceregulations

[21] D. Yang, T. Sinha, D. Adamson, and C. P. Rose, "Turn on, tune in, drop out," Anticipating student dropouts in Massive Open Online Courses, NIPS Workshop on Data Driven Education, 2013.

[22] J DeBoer et al., "Diversity in MOOC students' backgrounds and behaviors in relationship to performance in $6.002 \mathrm{x}$," presented at the Sixth Learning International Networks Consortium Conference, 2013.

[23] (December 2013). How to Earn 40 Certificates: An Interview with China's MOOC Superstar. [Online]. Available: http://librarylearningspace.com/how-to-earn-40-certificates-an-intervi ew-with-chinas-mooc-superstar/

[24] M. Wen, D. Yang, and C. P. Rose, "Linguistic reflections of student engagement in massive open online courses," presented at ICWSM'14, 2014.

[25] J. Lodge. (December 2013). The failure of Udacity: Lessons on MOOC Quality. [Online]. Available: http://www.ecampusnews.com/top-news/udacity-lessons-mooc-229/ 
[26] L. Pappano. (September 2013). The Boy Genius of Ulan Bator. The New York Times. [Online]. Available: http://www.nytimes.com/2013/09/15/magazine/the-boy-genius-of-ula n-bator.html?ref=education\&_r=0

[27] S. Kolowich. (February 2013). American council on education recommends 5 MOOCs for credit. The Chronicle of Higher Education. [Online]. Available: http://chronicle.com/article/American-Council-on-Education/137155/

[28] G. Ferenstein. (August 2013). Udacity and san jose state see improvement. Their Online Education Experiment. [Online]. Available: http://techcrunch.com/2013/08/28/californias-online-college-pilot-pro ves-successful-after-poor-results-in-1st-semester/

[29] J. Smialek. (August 2012). Free Online Classes Are Little Help in Job Hunt.

$$
\text { [Online]. }
$$

Available: http://www.businessweek.com/articles/2012-08-10/free-online-classe s-are-little-help-in-job-hunt

[30] EdX Open Source Platform Chosen to Power China's New Online Education Portal. (October 2013). [Online]. Available: http://edf.stanford.edu/readings/edx-open-source-platform-chosen-po wer-chinas-new-online-education-portal

[31] MOOC Masters: 5 Brilliant Professors You Must Take. [Online]. Available: http://students.approvedcolleges.com/top-mooc-professors-157/

[32] W. Live. (August 2013). The Benefits of Online Learning. [Online]. Available:

http://www.dailymotion.com/video/x15pjix_the-benefits-of-online-le arning_news

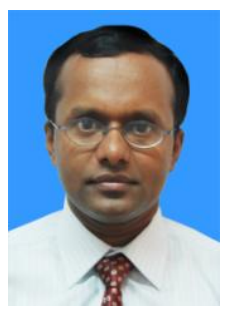

Laxmisha Rai received his B.E. (Mangalore University), and M. Tech (Manipal University) degrees from India, and Ph.D. in information and communication from Kyungpook National University, South Korea. Currently he is a professor at Shandong University of Science and Technology, Qingdao, China. His research interests include software engineering, real-time systems, embedded systems, autonomous mobile robots, expert systems, wireless sensor networks, and bilingual education. He has published over 30 research papers in international conferences, and journals and co-authored book titled "Programming in java with object-oriented features" (China University of Petroleum Press, 2012). He received "The Excellent Foreign Expert Award" from Provincial Government of China in 2003, and, "2005-LG-Best Research Paper Award" in the International SoC Design Conference, South Korea. In 2012, Dr. Rai received the "Qingdao Award" by the Qingdao Municipal People's Government of China, and in 2013 he received "Qilu Friendship Award", the highest recognition of Shandong Province, in recognition of the remarkable achievements made in Shandong Province of China. He is a member of IEEE (USA), International Association of Engineers (Hong Kong), and Asian Control Association.

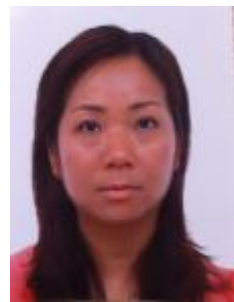

Deng Chun-Rao is a full-time lecturer who teaches English subject in the Hong Kong Polytechnic University, Hong Kong Community College. From 2007 to 2010, she received research studentship from the University of Hong Kong (HKU) and was awarded a PhD degree in 2011. Her research interests include second language education, communicative and task-based English language teaching approaches, as well as English curriculum and assessment. Dr. Deng has published several papers in international journals, such as Language Assessment Quarterly and Asian Journal English Language Teaching. 